\title{
Trachoma Elimination: Approaches, Experiences and Performance of Interventions in Amhara Regional State, Ethiopia
}

Bezuayehu Andualem ${ }^{1}$, Belay Beyene ${ }^{2 *}$, Melkamu Kassahun ${ }^{3}$, Addisu Kassa ${ }^{1}$, Mulat Zerihun ${ }^{4}$, Gizachew Wubetu ${ }^{5}$ and Abebaw Worku ${ }^{1}$

${ }^{1}$ Amhara NRS Health Bureau, Bahir Dar, Ethiopia

${ }^{2}$ Amhara National Regional State Health Bureau, Bahir Dar, Ethopia

${ }^{3}$ Health Promotion and Disease Prevention Core Process, Amhara National Regional State Health Bureau, Bahir Dar, Ethopia

${ }^{4}$ The Carter Center, Addis Ababa, Bahir Dar, Ethopia

${ }^{5}$ Department of Reproductive Health, Institute of Public, University of Gondar, Gondar, Ethopia

"Corresponding author: Belay Beyene, Amhara NRS Health Bureau/JSI-SEHP, Bahir Dar, Ethiopia, E-mail: fiametaye@gmail.com

Received date: January 3, 2018; Accepted date: March 20, 2018; Published date: March 28, 2018

Copyright: $\odot 2018$ Andualem B, et al. This is an open-access article distributed under the terms of the Creative Commons Attribution License, which permits unrestricted use, distribution, and reproduction in any medium, provided the original author and source are credited.

\begin{abstract}
Background: Trachoma is caused by conjunctival infection with a Bacteria, Chlamydia trachomatis. According to WHO grading system trachomatous trichiasis (TT), leads to irreversible blindness. Amhara national state of Ethiopia has the highest burden of TT. Despite huge efforts the region has big backlog and far from the target.

Methodology/Principal findings: We carried out a review and trend analysis on previous years of Trachoma intervention in the region. We also designed a logical frame work, which bring all actors together. Then the new approach of TT surgery intervention frame work "The MUST" was implemented. The regional total TT backlog as of June 2017 was found to be 245,504. From all the surgeries carried out between 2012 and mid-2017, 32\% (11687) was done only in 2016. All the ten zones of the region showed dramatic performance than ever after the new approach implemented in the region. East Gojjam [31.9\% (73742)] followed by South Gondar [12.3\% (28491)] zones took the highest share of TT surgery performances of the national regional state (NRS) during in the era of new approach reporting periods (2015-mid 2017). From the total of 23 districts (woredas) of the region which clear their TT backlog, eight of them are found to be in East Gojjam zone. South Gondar perform 36.4\% $(14,978)$ in 2016 from all the reporting periods of TT surgeries conducted during 2012-mid 2017. Facial cleanliness coverage among school children was found to be $90.4 \%$ and $90.8 \%$ in 2016 and mid 2017 respectively. Household latrine ownership coverage was $68.2 \%(6,805)$ and $68.5 \%(6772)$ during the same reporting periods respectively.
\end{abstract}

Conclusions: Amhara national state has still huge TT backlog. The new approach showed an assurance of clearing TT backlog before 2020. The sustainable intervention (hygiene and environmental) are not yet strong like treatment-based interventions.

Keywords Trachoma; Trachomatous trichiasis; Follicular; Blinding trachoma

\section{Background}

Trachoma causes blindness through repeated conjunctival infection with Chlamydia trachomatis [1]. Blinding trachoma is endemic in many of the poorest and most remote areas of 51 countries in Africa, Asia, Central and South America, Australia and the Middle East. Worldwide, an estimated 2.2 million people are visually impaired as a result of trachoma, of whom 1.2 million are blind. An estimated 232 million people living in trachoma-endemic districts are at risk. More than 21 million have active trachoma and about 7.3 million require surgery for trachomatous trichiasis [2]. With different estimates of scholars, the economic cost of trachoma is very high; productivity lost estimated US\$ 2.9 billion and economic loss estimated as high as US\$ 5.3 billion $[3,4]$.

Africa is the worst affected continent: 18 million cases of active trachoma (85\% of all cases globally) and 3.2 million cases of trichiasis (44\% of all cases globally) are thought to exist in 29 of the 47 countries in WHO's African Region. Ethiopia and South Sudan have the highest prevalence of active trachoma: in some areas of these countries, active disease is present in more than $50 \%$ of children aged $1-9$ years and trichiasis affects more than $10 \%$ of adults [2].

According to the 2005-6, Ethiopian national survey, prevalence of active trachoma (either TF or TI) for children in the age group 1-9 year was $40.14 \%$. Considerable regional variations are observed in the occurrence of active trachoma; the highest prevalence was in Amhara (62.6\%), Oromia (41.3\%), SNNP (33.2\%), Tigray (26.5\%), Somali (22.6\%) and Gambella (19.1\%). The rural prevalence of active trachoma is almost fourfold compared to the urban (42.5\% rural vs. $10.7 \%$ urban). The national prevalence of trachomatous trichiasis (TT) is $3.1 \%$ with the highest prevalence (5.2\%) in Amhara national regional state [5].

The World Health Organization (WHO) recommends surgery to reduce the risk of sight loss [6]. In the last decade, only about $50 \%$ of the annual global surgical targets have been achieved [7]. At the current rate, it has been estimated that the trichiasis backlog would not be adequately addressed until 2032, twelve years after the Global Elimination of Trachoma (GET) 2020 target date to eliminate blinding trachoma [8]. 
Since the establishment in 1998 of the Global Elimination of Trachoma by 2020 (GET2020) initiative, an increasing number of endemic countries have implemented national programmes incorporating the SAFE strategy of Surgery to correct trichiasis, Antibiotic to clear Chlamydia trachomatis infection, Facial cleanliness and Environmental improvement to reduce transmission. Morocco was one of the first countries in Africa to implement SAFE at the national level and achieved its Ultimate Intervention Goals (UIG) in 2006 [9]. The ultimate intervention goal (UIG) for trachoma control, defined by the World Health Organization (WHO) as "elimination as a public health problem", is achieving a transmission target: reducing trachomatous inflammation follicular in children aged 1-9 years (TF1-9) to less than 5\%, and a morbidity target: less than 1 case of trachomatous trichiasis (TT) per 1,000 people $[10,11]$.

Ethiopia has also made important progress in the elimination of trachoma. The annual number of azithromycin treatments administered has increased from year to year. The SAFE strategy is being implemented in full in many endemic areas. By 2013, a cumulative total of 855,491 trichiasis surgeries had been done; 133,940 surgeries were done in 2013 alone. Since the inception of mass drug administration (MDA) in 2006 with 400,000 antibiotic treatments, a cumulative total of 119,697, 067 treatments have been administered [12].

Close to $71 \%$ (184,192 number of people operated for trachomatous trichiasis) of the 2016 global output of trichiasis surgery was performed in Ethiopia [13]. Of the ten states in Ethiopia, Amhara National Regional State is disproportionately affected by trachoma, bearing an estimated minimum of $45 \%$ of the national trichiasis burden with approximately one in twenty of all adults suffering from trichiasis. This region has been known for the highest prevalence of active trachoma (62.6\%) and Trachomatous trichiasis (5.2\%) as mentioned above [5]. After tremendous efferts of diffrent interventions, the 2013-2014 district-based trachoma survey of the region showed active trachoma became $26.3 \%$. However, trachomatous trichiasis prevalence showed no progress (around 4\%) rather slightly increased after the 2006 national trachoma survey which was 3.8\%.

The difference of performance of TT surgery among administrative zones (provinces) of the region found very wide; with least in South Gonadr [28\% $(16,970)]$, North Gondar [13\% $(5,666)]$ and Awi zone [29 $(4,931)]$ and best in East Gojjam [177\% $(2,3814)]$ zone of the 10 zones in the state. This difference has been also shown in other related activities; for example; the Amhara Regional Sate Education Bureau baseline census in all primary schools revealed that only $68 \%$ of primary schools of South Gondar zone had functional latrine. Of these schools, only $20.8 \%$ of them had water in their compound for face and hand washing.

Based on the above-mentioned evidences, the Amhara NRS health bureau designed a new approach TT intervention-the 'MUST' framework (Multisectoral coordination, Universal and consistent support, Insure Sustainability, Test the performance) to solve the staggering problem and step the regional state in to the elimination target.

\section{Objective}

- To establish a platform of coordination among the different government sectors and supporting partners on trachoma intervention

- To clear the TT-Backlog
- To learn from lessons and new approaches during the processes of interventions

\section{Methods}

First, we reviewed previous Trachoma elimination performance of 10 zones of Amhara national regional state in Ethiopia; such as trends by time, availability of Trachoma program officers at zonal and district levels and trained health professionals at health facility level for TT surgery implementation. According to the 2016 update of planning unit of the Amhara health bureau, the the regional state has 10 zones, 3 city administrations, 169 woredas, and 3,437 kebeles with a total population of $21,134,999$. It has also 68 hospitals, 838 health centers and 3,336 health posts, 9 secondary eye care units and 313 primary eye care units, 8,611 primary schools, 106 program officers for Trachoma and other neglected tropical diseases (NTD), 391 TT surgeons and 1,688 TT sets.

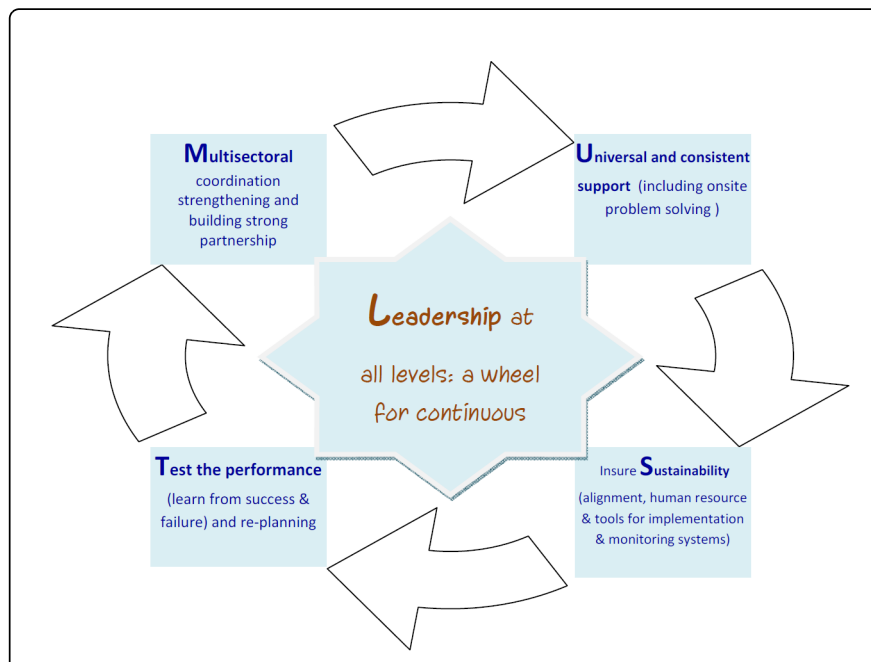

Figure 1: A logical frame work of TT surgery performance improvement, Amhara regional state, Ethiopia.

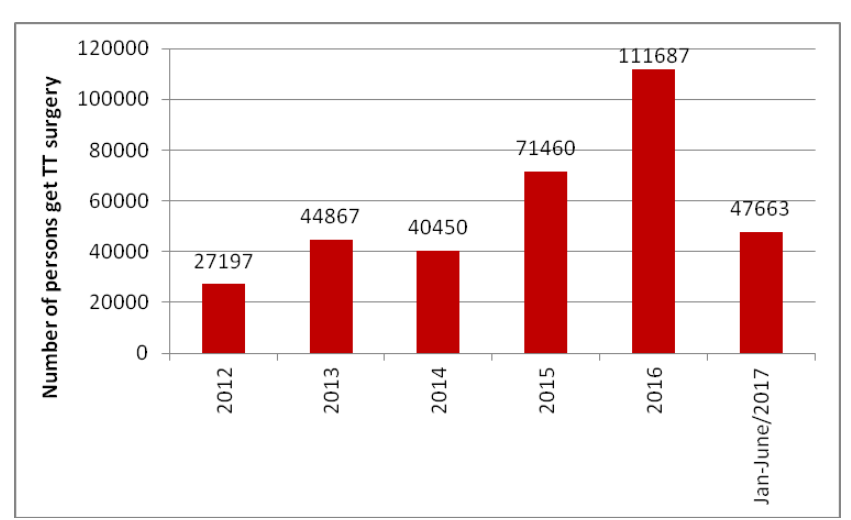

Figure 2: Number of TT surgeries carried out during 2012- mid 2017, Amhara NRS, Ethiopia.

After reviewing series of performances of TT burden of the regional state, the bureau developed a conceptual framework or a model (Figure 1) to intensify activities to rapidly decrease the burden of the disease. 
Citation: Andualem B, Beyene B, Kassahun M, Kassa A, Zerihun M, et al. (2018) Trachoma Elimination: Approaches, Experiences and Performance of Interventions in Amhara Regional State, Ethiopia. J Eye Dis Disord 3: 115.

Page 3 of 6

The frame work pillars include multisectoral coordination and governance, universal and consistent support, insuring sustainability, test the performance and re-plan for TT surgery implementation. Term of references (TOR) were developed and provided for each actor with orientation. A field visit also carried out to support and observe each actor's engagement, daily performance reports were reached at bureau level. Gaps of poor performer zones and districts were identified, and support provided. Then, we summarized both the qualitative and quantitative data.

\begin{tabular}{|l|l|l|l|l|l|l|l|l|}
\hline S. No & zone & $\mathbf{2 0 1 2}$ & $\mathbf{2 0 1 3}$ & $\mathbf{2 0 1 4}$ & $\mathbf{2 0 1 5}$ & $\mathbf{2 0 1 6}$ & Jan-June/2017 & Total \\
\hline 1 & Awi & 1369 & 1096 & 1746 & 1312 & 2686 & 3788 & 11997 \\
\hline 2 & East Gojjam & 1970 & 6152 & 6846 & 31083 & 31050 & 11609 & 88710 \\
\hline 3 & West Gojjam & 3270 & 6121 & 4775 & 5090 & 8468 & 6558 & 34282 \\
\hline 4 & North Gondar & 4895 & 4547 & 3298 & 5624 & 6787 & 3729 & 28880 \\
\hline 5 & South Gondar & 1354 & 5623 & 5712 & 6550 & 14978 & 6963 & 41180 \\
\hline 6 & North Shoa & 5115 & 7687 & 5541 & 5899 & 15841 & 1997 & 42080 \\
\hline 7 & North Wollo & 4545 & 4684 & 5149 & 6014 & 11229 & 5454 & 37075 \\
\hline 8 & Oromia & 596 & 612 & 579 & 738 & 1523 & 602 & 4 \\
\hline 9 & South Wollo & 2998 & 5848 & 5663 & 6898 & 14658 & 4315 & 4650 \\
\hline 10 & Waghemira & 1085 & 2497 & 1141 & 2252 & 4467 & 2648 & 40380 \\
\hline Regional Total & & $\mathbf{2 7 1 9 7}$ & $\mathbf{4 4 8 6 7}$ & $\mathbf{4 0 4 5 0}$ & $\mathbf{7 1 4 6 0}$ & $\mathbf{1 1 1 6 8 7}$ & $\mathbf{4 7 6 6 3}$ & $\mathbf{3 4 0 9 0}$ \\
\hline
\end{tabular}

Table 1: Number of TT surgery performance during 2012 to mid-2017 by zones of Amhara NRS, Ethiopia.

\section{Results}

A total of 343,324 TT surgeries had been performed in Amhara National Regional State of Ethiopia during 2012 to mid-2017. Of these $32 \%(111,687)$ of the TT surgeries carried out in the region were the 2016 fiscal year performance (Figure 2). East Gojjam [25.8\% $(88,710)]$ followed by North Shoa $[12.3 \%(42,080)]$ zones took the highest share of TT surgery performances of the national regional state (NRS) during the reporting periods (Table 1).

South Gondar showed dramatic increment of TT performance in 2016 (Figure 3). During 2015 and 2016 a total of 21,528 TT surgeries were carried out in South Gondar zone and $69.6 \%$ of them were achieved in 2016 alone.

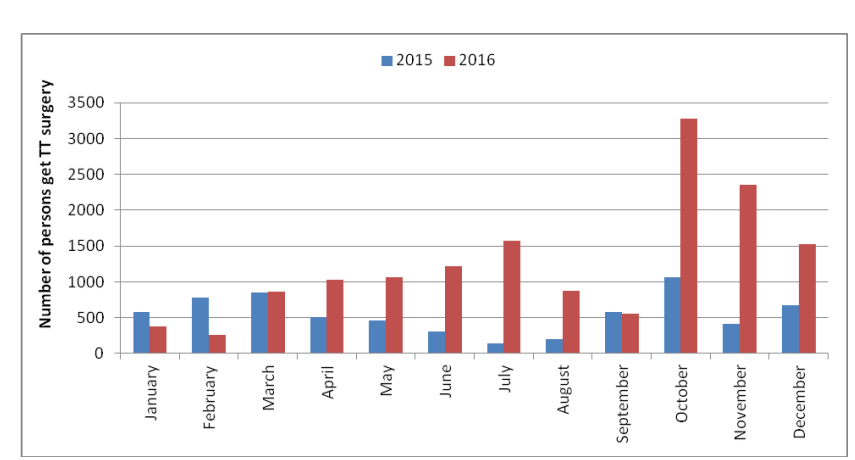

Figure 3: Monthly trend of TT surgery performance of South Gondar zone, Amhara NRS, Ethiopia, 2015-2016.

Gondar, South Wollo, West Gojjam and South Gondar zones of the State has high number of TT backlogs (Figure 4). As of June 2017, a total of 23 woredas of the regional state achieved clearing of TT backlog. East Gojjam and North Wollo zones perform the highest by having eight and six woredas cleared TT backlog respectively. No single woreda of West Gojjam, Oromia and South Wollo zones could clear TT backlog as of June 2017 (Figure 5).

TT surgery validation achievement of the regional sate during 2016 was $99.5 \%(6,230)$ and $98.6 \%$ (297) during Jan-June 2017. All zonal validation performance was found to be more than $90 \%$ (Table 2).

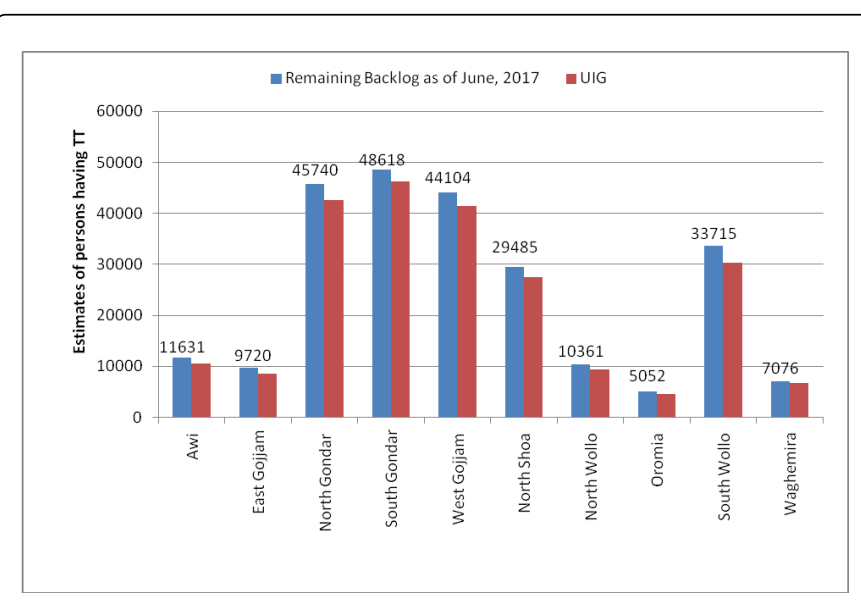

Figure 4: TT backlogs and UIG by zone, Amhara NRS, Ethiopia, 2017. 
Citation: Andualem B, Beyene B, Kassahun M, Kassa A, Zerihun M, et al. (2018) Trachoma Elimination: Approaches, Experiences and Performance of Interventions in Amhara Regional State, Ethiopia. J Eye Dis Disord 3: 115.

Page 4 of 6

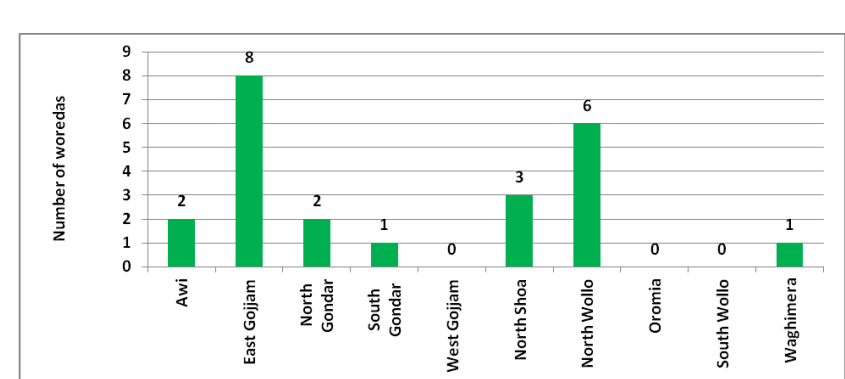

Figure 5: Number of woredas the cleared TT backlog in Amhara NRS, Ethiopia, 2017.

\begin{tabular}{|c|c|c|c|c|c|c|c|}
\hline \multirow{3}{*}{$\begin{array}{l}\text { S. } \\
\text { No. }\end{array}$} & \multirow{3}{*}{ Zone } & \multicolumn{3}{|c|}{ Annual-2016 } & \multicolumn{3}{|c|}{ January-June, 2017} \\
\hline & & \multirow{2}{*}{$\begin{array}{l}\begin{array}{l}\text { Persons } \\
\text { interviewe } \\
\text { d }\end{array} \\
\text { No. }\end{array}$} & \multicolumn{2}{|c|}{$\begin{array}{l}\text { Persons } \\
\text { operated }\end{array}$} & \multirow{2}{*}{$\begin{array}{l}\begin{array}{l}\text { Persons } \\
\text { interviewe } \\
\text { d }\end{array} \\
\text { No. }\end{array}$} & \multicolumn{2}{|c|}{$\begin{array}{l}\text { Persons } \\
\text { operated }\end{array}$} \\
\hline & & & No. & $\%$ & & No. & $\%$ \\
\hline 1 & Awi & 201 & 201 & 100 & 249 & 242 & 97.2 \\
\hline 2 & East Gojjam & 2949 & 2925 & $\begin{array}{l}99 . \\
2\end{array}$ & 182 & 169 & 92.9 \\
\hline 3 & North Gondar & 359 & 357 & $\begin{array}{l}99 . \\
4\end{array}$ & 239 & 238 & 99.6 \\
\hline 4 & South Gondar & 578 & 576 & $\begin{array}{l}99 . \\
7\end{array}$ & 471 & 468 & 99.4 \\
\hline 5 & West Gojjam & 325 & 325 & 100 & 578 & 570 & 98.6 \\
\hline 6 & North Shoa & 437 & 435 & $\begin{array}{l}99 . \\
5\end{array}$ & 726 & 721 & 99.3 \\
\hline 7 & North Wollo & 677 & 677 & 100 & 95 & 90 & 94.7 \\
\hline 8 & Oromia & 189 & 188 & $\begin{array}{l}99 . \\
5\end{array}$ & 53 & 53 & 100 \\
\hline 9 & South Wollo & 372 & 370 & $\begin{array}{l}99 . \\
5\end{array}$ & 230 & 230 & 100 \\
\hline 10 & Waghimera & 176 & 176 & 100 & 126 & 126 & 100 \\
\hline Tota & & 6263 & 6230 & $\begin{array}{l}99 . \\
5\end{array}$ & 2949 & 2907 & 98.6 \\
\hline
\end{tabular}

Table 2: Distribution of TT surgery validation findings by zone, Amhara NRS, Ethiopia, 2016-2017.

The regional facial cleanliness assessment among children during 2016 and mid 2017 was $92.4 \%$ (42621) and 90.8\% (74866) respectively. East Gojjam achieved the highest [97.3\% (8847)] and Waghimra zone found to be the least [83.1\% (2069)] achiever in facial cleanliness (Table 3).

Regarding, the household latrine ownership, the regional performance with the above similar reporting periods was $68.2 \%$ $(6,805)$ and $68.5 \%(6,772)$ respectively. North Gondar zone performance was found low $(41 \%, 537)$ and Awi zone performed the highest $(81 \%, 629)$ during mid 2017 (Table 4).

\begin{tabular}{|c|c|c|c|c|c|c|c|}
\hline \multirow{3}{*}{$\begin{array}{l}\text { S. } \\
\text { No }\end{array}$} & \multirow{3}{*}{ Zone } & \multicolumn{3}{|c|}{ Annual-2016 } & \multicolumn{3}{|c|}{ Jan-June 2017} \\
\hline & & \multirow{2}{*}{$\begin{array}{l}\text { Children } \\
\text { assesse } \\
\text { d }\end{array}$} & \multicolumn{2}{|c|}{$\begin{array}{l}\text { Children with } \\
\text { Clean face }\end{array}$} & \multirow{2}{*}{$\begin{array}{l}\begin{array}{l}\text { Children } \\
\text { assessed }\end{array} \\
\mathbf{N}\end{array}$} & \multicolumn{2}{|c|}{$\begin{array}{l}\text { Children with } \\
\text { Clean face }\end{array}$} \\
\hline & & & $\mathbf{N}$ & $\%$ & & $\%$ & \\
\hline 1 & Awi & 3748 & 3474 & 92.7 & 6252 & 5824 & 93.2 \\
\hline 2 & East Gojjam & 5533 & 5346 & 96.6 & 9090 & 8847 & 97.3 \\
\hline 3 & North Gondar & 9481 & 8797 & 92.8 & 10585 & 9129 & 86.2 \\
\hline 4 & South Gondar & 3987 & 3284 & 82.4 & 8542 & 7410 & 86.7 \\
\hline 5 & West Gojjam & 5107 & 4784 & 93.7 & 8712 & 7854 & 90.2 \\
\hline 6 & North Shoa & 4508 & 4300 & 95.4 & 18808 & 17922 & 95.3 \\
\hline 7 & North Wollo & 2670 & 2465 & 92.3 & 3100 & 2742 & 88.5 \\
\hline 8 & Oromia & 1503 & 1441 & 95.9 & 913 & 867 & 95 \\
\hline 9 & South Wollo & 6990 & 6631 & 94.9 & 13965 & 12202 & 87.4 \\
\hline \multirow[t]{2}{*}{10} & Waghmare & 2577 & 2099 & 81.5 & 2490 & 2069 & 83.1 \\
\hline & Total & 46104 & 42621 & 92.4 & 82457 & 74866 & 90.8 \\
\hline
\end{tabular}

Table 3: Facial cleanliness assessment finding among children, Amhara NRS, Ethiopia, 2016-2017.

\begin{tabular}{|c|c|c|c|c|c|c|c|}
\hline \multirow{3}{*}{$\begin{array}{l}\text { S. } \\
\text { No }\end{array}$} & \multirow[b]{3}{*}{ Zone } & \multicolumn{3}{|c|}{ Annual-2016 } & \multicolumn{3}{|c|}{ Jan-June 2017} \\
\hline & & \multirow{2}{*}{$\begin{array}{l}\text { HHs } \\
\text { visited }\end{array}$} & \multicolumn{2}{|c|}{$\begin{array}{l}\text { HHs with } \\
\text { Latrine }\end{array}$} & \multirow{2}{*}{$\begin{array}{l}\begin{array}{l}\text { HHs } \\
\text { visited }\end{array} \\
\text { No. }\end{array}$} & \multicolumn{2}{|c|}{$\begin{array}{l}\text { HHs with } \\
\text { Latrine }\end{array}$} \\
\hline & & & No. & $\%$ & & $\%$ & \\
\hline 1 & Awi & 833 & 671 & 80.6 & 777 & 629 & 81 \\
\hline 2 & East Gojjam & 1396 & 1107 & 79.3 & 1413 & 1133 & 80.2 \\
\hline 3 & North Gondar & 1714 & 951 & 55.5 & 1311 & 537 & 41 \\
\hline 4 & South Gondar & 907 & 714 & 78.7 & 1225 & 924 & 75.4 \\
\hline 5 & West Gojjam & 902 & 689 & 76.4 & 1336 & 845 & 63.2 \\
\hline 6 & North Shoa & 1060 & 643 & 60.7 & 1134 & 796 & 70.2 \\
\hline 7 & North Wollo & 441 & 250 & 56.7 & 306 & 211 & 69 \\
\hline 8 & Oromia & 702 & 307 & 43.7 & 484 & 277 & 57.2 \\
\hline 9 & South Wollo & 1174 & 811 & 69.1 & 1287 & 975 & 75.8 \\
\hline 10 & Waghimera & 852 & 662 & 77.7 & 614 & 445 & 72.5 \\
\hline \multicolumn{2}{|c|}{ Total } & 9981 & 6805 & 68.2 & 9887 & 6772 & 68.5 \\
\hline
\end{tabular}

Table 4: Household latrine assessment finding in Amhara NRS, Ethiopia, 2016-2017. 


\begin{tabular}{|c|c|c|c|}
\hline $\begin{array}{l}\text { Multisectoral coordination } \\
\text { strengthening and building strong } \\
\text { partnership }\end{array}$ & $\begin{array}{l}\text { The regional health bureau launched the fast track initiative } \\
\text { to eliminate TT backlog in the region, allocated budget to } \\
\text { each zone, assigned health workers responsible for eye care } \\
\text { service to all districts, engage all political leaders to lead and } \\
\text { monitored the TT and over all eye care service Leaders well } \\
\text { advocated and communicated the burden of TT and TT } \\
\text { surgery campaigns Multisectoral and multiagency Wash } \\
\text { Taskforce established, Performance monitoring of each zone } \\
\text { and district conducted Engagement of sectors and NGOs } \\
\text { also monitored and guided Prioritization and clustering of } \\
\text { districts carried out }\end{array}$ & $\begin{array}{l}\text { Leaders chaired and reviewed } \\
\text { performances, Allocated Budget for } \\
\text { activities, Communities well involved } \\
\text { and showed great interest in all } \\
\text { campaigns. Taskforce meeting carried } \\
\text { out regularly with good multisectoral } \\
\text { representation. Sectors r like } \\
\text { communication and mass media agency } \\
\text { successfully provided awareness } \\
\text { creation through radio and television } \\
\text { spots, healthy school program } \\
\text { addressed students on eye care health } \\
\text { promotion, safe water supply provided } \\
\text { such as construction of hand dug wells } \\
\text { construction \& Term of references and } \\
\text { implementation manuals produced. }\end{array}$ & \multirow{4}{*}{$\begin{array}{l}\text { All over burden of TT } \\
\text { decreased across the } \\
\text { region although still } \\
\text { backlog are persistent, } \\
\text { Least performing } \\
\text { zones in TT surgery } \\
\text { like South Gondar } \\
\text { showed dramatic } \\
\text { improvement in 2016, } \\
\text { Quality data base } \\
\text { established kept at } \\
\text { NRS health bureau } \\
\text { level, which never } \\
\text { existed before. }\end{array}$} \\
\hline $\begin{array}{l}\text { Universal and consistent support } \\
\text { (including onsite problem solving) }\end{array}$ & $\begin{array}{l}\text { Support has been provided to all zones and districts/woredas } \\
\text { such as allocating budget, hiring qualified professionals, } \\
\text { providing training, etc }\end{array}$ & $\begin{array}{l}\text { Most Zones and districts developed Self } \\
\text { learning and innovation on problem } \\
\text { solving capabilities (find a way to hire } \\
\text { and train health workers to implement } \\
\text { TT surgery) }\end{array}$ & \\
\hline $\begin{array}{l}\text { Insure Sustainability (alignment, } \\
\text { utilization of human resource \& } \\
\text { tools for implementation \& } \\
\text { monitoring systems) }\end{array}$ & $\begin{array}{l}\text { Monitoring and evaluation sustained throughout the year } \\
\text { (regular weekly and monthly report of TT surgeries } \\
\text { submission from each zone and district/woreda and timely } \\
\text { feedback provided). Facial cleanliness and latrine utilization } \\
\text { continuously advocated }\end{array}$ & $\begin{array}{l}\text { All zones and districts keep-up } \\
\text { continuous work on TT surgery and } \\
\text { other eye care services to improve eye } \\
\text { health of the community. Coverage of } \\
\text { facial cleanliness improved. }\end{array}$ & \\
\hline $\begin{array}{l}\text { Test the performance (learn from } \\
\text { success \& failure) and re-planning }\end{array}$ & $\begin{array}{l}\text { Each zone and district/woreda review its performance every } \\
\text { quarter, biannually and annually. Regional health bureau } \\
\text { points out the challenges, weakness and success of } \\
\text { activities. Tremendous effort done to take off the ownership, } \\
\text { political commitment at all levels (regional, zonal, district/ } \\
\text { woreda, health facility and kebele/village levels, \& Re-plan } \\
\text { for further better performance. }\end{array}$ & $\begin{array}{l}\text { All zones and woredas performance on } \\
\text { TT surgery improved during } 2016 \text { and } \\
2017 \text { than the previous years. Validation } \\
\text { of surgeries for quality carried out in } \\
\text { each district after all campaigns. } \\
\text { Lessons well documented and evidence } \\
\text { based plan produced. }\end{array}$ & \\
\hline
\end{tabular}

Table 5: Strategies, major activities, outputs and outcomes, 2016-2017.

\section{Discussion}

When we look at the yearly trend of the regional TT surgery performance, the case of 2016 performance urge us to question why it became unique? TT surgery of 71,460 persons in 2015 vs. 111,687 persons in 2016; which has $64 \%$ difference in the same region and same health care system. We can find also a similar dramatic shift, when we look the monthly trends of 2015 and 2016 TT surgery performance of South Gondar zone (Figure 3). It also indicated that October 2016 performance alone competes to the half year performance of the past 10 years (Figure 3). Moreover, it is more than the 2008 annual performance. This could be due to the frequent field support of senior program managers and the establishment of intensified daily performance reporting system during the beginning of October 2016. This could be explained by the paradigm shift due to the fast track initiative of the federal ministry of health which alarmed the Amhara NRS health bureau leadership to take and design a unique framework which never be in its working desk. District level Trachoma and NTD program officers found to be key in improving the performance of trachoma intervention. During this exercise program managers and leaders well understood the gabs and $62.7 \%$ of district positions became fulfilled in the state. However, TT surgeons and other eye care professionals are also scarce. A study conducted in the same region indicated retention of trichiasis surgeons could improve productivity in TT clearing backlog [14], which supports the idea of looking in to retention mechanisms in line with training of new professionals.
East Gojjam zone uniquely perform huge backlogs compared from other zones of the regional sate almost equally both in 2015 and 2016 (31,083 and 31,050 surgeries respectively). This could be due to the launching of regional fast track initiative at Debre Markos town, a capital of East Gojjam zone during early 2015 which strengthened the ownership and political commitment. The other issue could be due to the fact that East Gojjam zone had the highest burden of trachoma prevalence in the regional state. Because of this remarkable success, irrespective of its big population size and highest prevalence of Trachoma, East Gojjam zone became one of the zones having the least number of TT backlog in the regional state (Figure 4).

Trachoma Elimination through sustainable interventions:

More than $80 \%$ of communicable diseases in Ethiopia are believed to be preventable using hygiene and environmental health interventions. Our framework faced challenges related to environmental health interventions. We know in the framework/ model that multisectoral and/or multiagency coordination, leadership, governance and partnership are vital pillars of implementation processes to secure the issue of Trachoma Elimination through sustainable interventions. Water, sanitation and hygiene (Wash) related interventions were difficult to successfully implement during all the cycles of our logical framework ('The MUST model'). The coverage of facial cleanliness among children (Table 3) seems good, but coverage of latrine ownership based on the rapid assessment found low (Table 5). But, we get a lesson that political leadership and senior program managers of different sectors role found to be vital in realizing the intervention at community level. From previous experiences and with 
Citation: Andualem B, Beyene B, Kassahun M, Kassa A, Zerihun M, et al. (2018) Trachoma Elimination: Approaches, Experiences and Performance of Interventions in Amhara Regional State, Ethiopia. J Eye Dis Disord 3: 115.

Page 6 of 6

the current understanding; Safe surgery and Mass Antibiotic provision components could not smoothly embrace Facial cleanliness \& Environmental intervention components to build technical confidence on trachoma elimination.

In conclusion, Amhara national regional state of Ethiopia has still huge TT backlog. The regional health bureau's new approach (The MUST frame work) showed an assurance of clearing TT backlog as quick as possible before 2020. The Multisectoral coordination and governance, Universal and consistent support at all levels, Insuring sustainability with effective implementation of intervention, Testing the performance and learn from lessons (The MUST framework) dramatically improved TT surgery performance throughout the region. Therefore, the following recommendations better be considered to continuously improve achievements.

The regional sate health bureau has to strengthen reviewing of performances, regular supportive supervision, the daily, weekly and monthly reporting systems at each level. Political leaders at all levels (regional sate, zonal, district and village/kebele) should fully involve to clear TT backlog and work closely on sustainable interventions. The regional state health bureau should also intensify the training of midlevel eye care workers and Wash professionals and strengthen the coordination for integration of Trachoma with other NTDs Taskforce. This lesson could be scalable to other disease control and prevention programs with further development.

\section{Acknowledgments}

Authors cordially acknowledge the following organization for their unreserved support and full involvement to realize this exercise; To the people of Amhara NRS, health offices, administration offices, education and water offices at all levels, The Amhara NRS, ministry of health of Ethiopia, the carter Center, Lions Clubs International Foundation, International Trachoma Initiative, UKaid /DFID, USAIDJSI/SEUHP and to those that we could not list out them all here.

\section{References}

1. Gambhir M, Basanez MG, Burton MJ, Solomon AW, Bailey RL, et al (2009) The development of an age-structured model for trachoma transmission dynamics, pathogenesis andcontrol. PLoS Negl Trop Dis 3: e462.

2. http://www.who.int/trachoma/epidemiology/en/_ accessed on 12/9/2017.

3. Frick KD, Hanson CL, Jacobson GA (2003) Global burden of trachoma and, economics of the disease. Am J Trop Med Hyg 69: 1-10.

4. Frick KD, Basilion EV, Hanson CL, Colchero MA (2003) Estimating the burden and economic impact of trachomatous visual loss. Ophthalmic Epidemiol 10: 121-132.

5. Yemane B, Alemayehu W, Abebe B, Liknaw A, Wondu A, et al. (2007) Prevalence of Trachoma in Ethiopia. Ethiop J Health Dev 21.

6. World Health Organization (2013) Trichiasis Surgery for Trachoma.

7. Solomon A (2014) WHO Alliance for the Global Elimination of Blinding Trachoma by the year 2020. Progress report on elimination of trachoma, 2013. Weekly epidemiological record 89: 421-428.

8. International Coalition for Trachoma Control (ICTC) (2011) The end in sight: A global strategy to eliminate blinding trachoma.

9. Smith JL, Flueckiger RM, Hooper PJ, Polack S, Cromwell EA, et al.(2013) The Geographical Distribution and Burden of Trachoma in Africa. PLoS Negl Trop Dis 7: e2359.

10. Resnikoff S, Huguet P, Mariotti SP (2007) Certification of the elimination of blinding trachoma by the World Health Organization. Rev Int Trach Pathol Ocul Trop Subtrop Sante Publique 84: 59-68.

11. King JD, Teferi T, Cromwell EA, Zerihun M, Ngondi JM, et al. (2014) Prevalence of Trachoma at Sub-District Level in Ethiopia: Determining When to Stop Mass Azithromycin Distribution. PLoS Negl Trop Dis 8: e2732.

12. WHO (2014) Report of the 18th meeting of the WHO Alliance for the Global Elimination of Trachoma by 2020. Addis Ababa, 28-29.

13. WHO (2017) Weekly Epidemology Record, No 26.

14. Habtamu E, Rajak SN, Gebre T, Zerihun M, Genet A, et al. (2015) Clearing the Backlog: Trichiasis Surgeon Retention and Productivity in Northern Ethiopia. PLoS Negl Trop Dis 5: e1014. 